providers in various cultural settings. Moreover, the cost-effectiveness of scaling up interventions deemed to be a crucial consideration in the management of other mental health conditions should also apply to gaming disorder.

\section{Data availability}

Data availability is not applicable to this article as no new data were created or analysed in this study.

\section{Funding}

This research received no specific grant from any funding agency, commercial or not-for-profit sectors.

\section{Declaration of interest}

H.E. is a member of the BJPsych International editorial board and did not take part in the review or decision-making process of this paper.

\section{References}

1 American Society of Addiction Medicine. Definition of addiction. ASAM, 2019 (https://www.asam.org/quality-care/definition-ofaddiction)

2 Narasimha VL, Butner J, Hanafi E, Farokhnia M, Bhad R, Chalabianloo $\mathrm{F}$, et al. Harm reduction and abstinence-based models for treatment of substance use disorders during the COVID-19 pandemic: a global perspective. BJPsych Int [Epub ahead of print] 24 Feb 2022. Available from: https://doi.org/10. 1192/bji.2022.1.

3 Mohaddes Ardabili H, Akbari A, Rafei P, Butner J, Khan R, Khazaal Y, et al. Tramadol, captagon and khat use in the Eastern Mediterranean region: opening Pandora's box. BJPsych Int [Epub ahead of print] 19 Nov 2021. Available from: https://doi.org/10. 1192/bji.2021.53.

4 Long J, Bhad R, Potenza MN, Orsolini L, Phan V, Kanabar M, et al Public health approaches and policy changes after the inclusion of gaming disorder in ICD-11: global needs. BJPsych Int [Epub ahead of print] 9 Dec 2021. Available from: https://doi.org/10.1192/bji.2021.57.

\title{
THEMATIC \\ Tramadol, captagon and khat use in the PAPER Eastern Mediterranean Region: opening Pandora's box
}

\author{
Hossein Mohaddes Ardabili, ${ }^{1} \odot$ Abolfazl Akbari, ${ }^{2} \odot$ Parnian Rafei, ${ }^{3}$ \\ JL Butner, ${ }^{4}$ Riaz Khan, ${ }^{5}$ Yasser Khazaal, ${ }^{6}$ Abdulmalik Zuhair Arab, ${ }^{7}$ \\ Mohammed Rafiq Qazizada, ${ }^{8}$ Basma Al-Ansari ${ }^{9}$ and \\ Alexander Mario Baldacchino ${ }^{10}$
}

${ }^{1}$ Psychiatry Resident, Psychiatry and Behavioral Sciences Research Center, Mashhad University of Medical Sciences, Mashhad, Iran: and International Society of Addiction Medicine New Professionals Exploration, Training \& Education Committe (SAM NExT), Calgary, Canada ${ }^{2}$ Medical Student, Student Research Committee, Faculty of Medicine, Mashhad University of Medical Sciences, Mashhad, Iran ${ }^{3}$ MSc. Clinical Psychology, Department of Psychology, Faculty of Psychology and Education, University of Tehran, Iran; and International of Tehran, Iran; and International
Society of Addiction Medicine New Society of Addiction Medicine New Professionals Exploration, Training \& Education Comm Calgary, Canada

${ }^{4}$ Addiction Medicine Specialist, International Society of Addiction Medicine New Professionals Exploration, Training \& Education Committe (ISAM NExT), Calgary, Canada ${ }^{5}$ Professor, Psychiatry Specialist, Department of Psychiatry, Frontier Medical College. Affilier Medical College, Affiliated to Bahria University, Abbottabad, Pakistan

${ }^{6}$ Full Professor of Addiction Psychiatry, Addiction Medicine Department of Psychiatry, Lausanne University Hospital and Lausanne University, Switzerland
As defined by the World Health Organization, the Eastern Mediterranean Region (EMR), given its special geopolitical situation and internal/external conflicts, faces an increase in illegal activities such as drug production and trafficking, highlighting the need for a comprehensive understanding of the substance use situation. On the basis of a review of published papers between 2015 and 2021 we briefly review substance use in the EMR with special focus on the emerging drugs pertinent to this region, namely tramadol, captagon and khat.

\section{Background}

According to World Health Organization (WHO) classification, the Eastern Mediterranean Region (EMR) comprises 22 countries with a total population of nearly 679 million. ${ }^{1}$ These countries are: Afghanistan, Bahrain, Djibouti, Egypt, Iran (Islamic Republic of), Iraq, Jordan, Kuwait, Lebanon, Libya, Morocco, Oman, Pakistan, Palestine, Qatar, Saudi Arabia, Somalia, Sudan, Syrian Arab Republic, Tunisia, United Arab Emirates and Yemen.
The prevailing situation of war, insurgencies, political conflict and civil unrest in many countries of the region has dramatically influenced substance use problems in every aspect, from production and trafficking to availability and pattern of use. This is compounded by the long-standing position of this region as one of the largest opium production sites globally. ${ }^{2}$ These instabilities prevent health and social care systems from providing and sustaining harmonised and integrated effective services. Additionally, increased production and availability of different types of stimulant, especially captagon, has also become a major drug problem in the region ${ }^{3}$ (Fig. 1). From the information available the general situation of substance use in the EMR region indicates that in 2017 about 4.2 million disability-adjusted life-years (DALYs) were lost due to substance use disorders ${ }^{7}$ (Fig. 2). The regional estimated crude death rate due to substance use disorders in 2015 was reported as 1.5 per 100000 population, which has not changed since $2000 .{ }^{10}$ Although this is lower than the global estimate in 2015 (2.3/100000), the figures should be carefully considered owing to possible weaknesses in the collection of the epidemiological data. 
'PG Researcher, Division of Systems Medicine, School of Medicine, University of Dundee, UK ${ }^{8}$ Dr., Communicable Diseases Control Directorate, National AIDs Control Program,

Communicable Diseases Control Directorate, Ministry of Public Health, Kabul, Afghanistan

PhD Addiction Medicine, Addiction Medicine, Sydney Medical School, University of Sydney, NSW, Australia

${ }^{10}$ Medicine, Psychiatry and Addictions Professor, Division of Population and Behavioural Science, School of Medicine, University of St Andrews, UK. mail amb30@st-andrew

*A video abstract is available for this paper at: https://vimeo.com/ bjpsych/bji-2021-53

Keywords. Epidemiology; Eastern Mediterranean region; khat; tramadol; captagon.

First received 8 May 202 Final revision 5 Aug 2021

doi:10.1192/bji.2021.53

(c) The Author(s), 2021. Published by Cambridge University Press on behalf of the Royal College of Psychiatrists. This is an Open Access article, distributed under the terms of the Creative

Commons Attribution licence (https://creativecommons.org/ licenses/by/4.0/), which permits unrestricted re-use, distribution, and reproduction in any medium, provided the original work is properly cited.

\section{Pattern of substance use in the region}

The EMR has been the scene of prominent production and seizure of opioids, cocaine, amphetamine-type stimulants and khat.

\section{Opioids}

Opioids remain the main cause of mortality related to use of illicit substances in the region. The second- and third-highest global death rates per 100000 from opioid overdoses occur in Libya and the United Arab Emirates (UAE) respectively. ${ }^{11}$ Also, opium smoking is a traditional practice in countries such as Afghanistan, Iran and Iraq.

Tramadol is an opioid that is widely used to treat moderate to severe pain and has also been used off-label in the treatment of sexual dysfunction such as premature ejaculation. There is growing evidence of non-medical use of tramadol in the EMR, reflected in the number of people in treatment for tramadol-related problems and the number of tramadol overdose deaths reported in some countries, particularly among young people. ${ }^{12}$ Different studies have concluded that the high levels of misuse of tramadol are a result of its easy availability in pharmacies (including without medication refills in some of these countries) and illicit markets, low price compared with illicit drugs, perceptions among users that tramadol is safe as it is a prescription medication, and the ease with which it can be hidden. Having in mind that less than $10 \%$ of tramadol users have a medical source, ${ }^{13}$ the non-medical use of tramadol has been reported by many countries, including Egypt, Iran, Jordan, Lebanon, Libya, Qatar, Saudi Arabia and the UAE. Among Egyptian adolescents, tramadol use is more prevalent than heroin. ${ }^{14}$ Tramadol use in the Iranian general population has been estimated at $4.9 \%$ among males and $0.8 \%$ among females. ${ }^{15}$ Increasingly, tramadol has been placed under national control in most EMR countries and is therefore only legally accessible by prescription. Such tight control is concerning because it may restrict the medical use of tramadol, particularly in countries of the region where regulatory mechanisms make other opioids (opioid agonist treatments for opiate addiction) less available for medical use.

\section{Amphetamine-type stimulants, including captagon}

The increasing trend of clandestine manufacture and use of amphetamine-type stimulants has become a major concern in countries such as Iran, Morocco and Pakistan. There is also a high demand for fenethylline (captagon) tablets in some countries of the region, especially in Syria, Lebanon and countries in the Arabian Peninsula. ${ }^{16}$ Captagon ${ }^{\circledR}$ was first introduced for its beneficial effects on hyperactivity, depression and narcolepsy, but its addictive and hallucinogenic features made it a popular illegal psychoactive substance. ${ }^{17}$ Captagon ${ }^{\circledR}$ itself is no longer manufactured and counterfeit captagon tablets are mostly combined with amphetamine, caffeine, ephedrine, quinine, theophylline acetaminophen and diphenhydramine and may cause unpredictable complications. ${ }^{3}$ In Saudi Arabia, there are more treatment admissions registered as a result of captagon use than opioid use. ${ }^{18}$

In addition to the established patterns, there have been emerging regional trends of substance use not only related to cultural and geographical

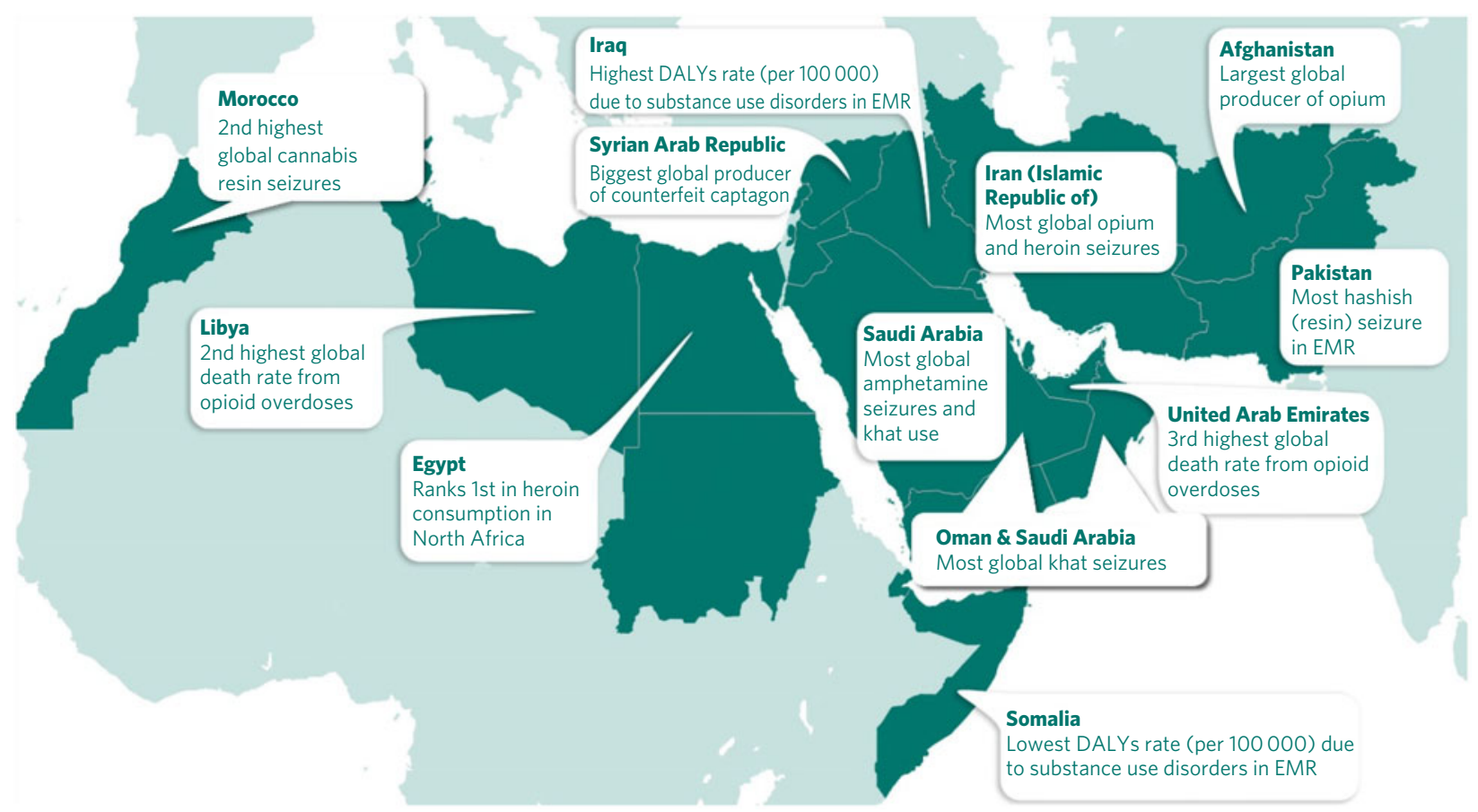

Fig. 1

Impact of drugs in the Eastern Mediterranean region (EMR). ${ }^{4-6}$ DALY, disability-adjusted life-year. 


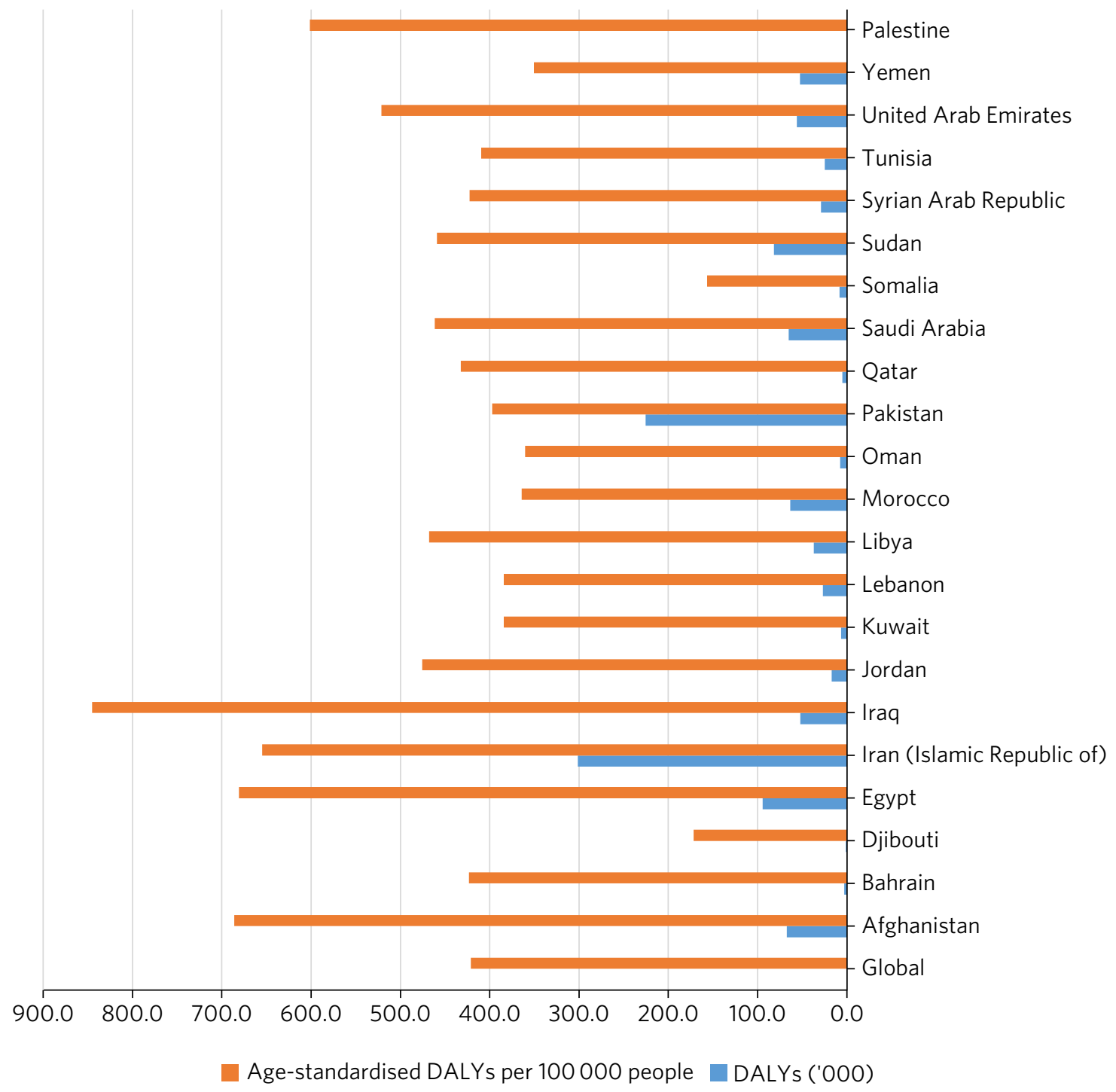

Fig. 2

Age-standardised disability-adjusted life-years (DALYs) per 100000 people (2016) and total DALYs ('000) (2015) in the Eastern Mediterranean region compared with the global estimate. 8,9 Some data were not available.

expectations in the region but also as a result of the large number of displaced populations. Captagon is an illustration of this trend. ${ }^{19} \mathrm{~A}$ novel concern about captagon use in Syria and neighbouring countries is that soldiers from all parties to the conflict use the drugs as combat stimulants ('chemical courage'). ${ }^{17}$ Meantime the current unstable situation in Syria has forced some traffickers to move production of captagon to Libya, Jordan, the UAE, Saudi Arabia and Sudan. ${ }^{19}$

\section{Khat}

Catha edulis, commonly known as khat, is a flowering plant growing in the khat belt countries in the Horn of Africa and the Arabian Peninsula. Khat misuse and dependency is still the major illicit substance use-related problem in countries such as Djibouti, Yemen, Somalia and southern provinces of Saudi Arabia. ${ }^{20}$ Most of the effect of chewing khat is thought to come from two chemicals that are structurally related to amphetamine. In Saudi Arabia, khat use is mostly prevalent in the Jazan region in the south of the country on the Yemeni border. A community-based study conducted in the Jazan region reported an overall prevalence of $29 \%$ of current khat chewing among respondents. Khat chewing was about four times higher among males than females in both current and lifetime users. ${ }^{21}$ It is reported that nearly $67.9 \%$ of adults in Yemen have at least one lifetime episode of khat use. ${ }^{20}$

People who use khat frequently report increased levels of energy, alertness and selfesteem, better ability for communication, sensations of elation, enhanced imaginative ability and a greater capacity for associating ideas. The literature suggests that khat use is associated with personal/public health and social problems. Khat chewing might reduce productivity 
- Within the EMR there is increasing use of opioids (tramadol) and stimulants (captagon and khat) outside the usual cultural and/or medical boundaries for these potentially psychoactive substances.

- Regional political instabilities have fuelled the use, production and trafficking of these substances, potentially creating problems within healthcare systems.

- Being known as the traditional production and trafficking hub for various drugs demands the importance and need for more attention to control the substance use situation in the EMR. This can only be achieved with reliable and accurate data collection.

- The exclusive video abstract (available at: https://vimeo.com/bjpsych/bji-2021-53) also summarizes the key points of this paper.

considering the large amount of time individuals spend on khat chewing. Additionally, another group of studies suggested a possible association between heavy khat consumption and psychosis. $^{22}$

\section{Multiple substance use}

Multiple substance use is a common practice in the EMR and adulterated substances available on the drug market have added to the vulnerability of people with substance use to various health hazards, making the clinical picture of drug intoxication complicated. For example, in some countries of the EMR people have added amphetamine-type stimulant use to opium use - drugs with completely different profiles of intoxication and withdrawal symptoms. ${ }^{23}$ Amphetamine-type stimulant use by patients under methadone maintenance treatment, especially women, is also a potential threat to treatment success. ${ }^{24}$ Lead poisoning among people who use opium has been a problem predominantly observed in Iran due to the impurity of opium products. ${ }^{25}$ The impurity of drugs might be due to the addition of heavy metals by local retailers, to produce heavier packages and therefore higher prices. ${ }^{26}$ The other routine scenario is adding hallucinogens or sedatives or even other pharmacological formulas to improve the experience of the person who uses the drug. ${ }^{27}$ Therefore, many people who have used a single street substance may present with a mixed clinical picture.

\section{Conclusions}

The EMR has a unique nature due to the presence of conflict and emergency in a number of countries. One may hypothesise that a combination of (a) social instability with additional increase in forcibly displaced populations, (b) increased demand in these substances for personal consumption by the affected heterogenous populations in the region and involved combatants, as well as (c) the enhanced production and distribution of these emerging drug markets has synergistically created the 'perfect storm' across the Eastern Mediterranean countries. This heterogeneity is reflected in the hybrid pattern of substance use and the emergence of new trends. The presence of a significant number of populations on the move due to internal displacement or migration affects the capacity of national health systems to effectively manage the evergrowing substance use problem and to meet the needs of the population. Accurate epidemiological data are needed to allow a better understanding of the impact of this problem on both general and marginalised populations.

Key points of this article are summarised in Box 1.

\section{Supplementary material}

Supplementary material is available online at https://doi.org/10. 1192/bji.2021.53.

\section{Data availability}

Data availability is not applicable to this article as no new data were created or analysed in this study.

\section{Acknowledgements}

We thank Mahdi Amiri (Student Research Committee, Faculty of Medicine, Mashhad University of Medical Sciences, Mashhad, Iran) for his efforts in designing the video abstract (https:// vimeo.com/bjpsych/bji-2021-53) and Faezeh Shahalami (Department of English Literature, Allameh Tabataba'i University, Tehran, Iran) for her contribution in recording narrations for the video abstract.

\section{Author contributions}

All the authors contributed to the conception of the paper. A.A., H.M.A. and A.M.B. reviewed the literature and drafted the first versions of the textual content and figures; all ten authors then revised it and added their comments. H.M.A. and A.A. finalised the manuscript, which was finally approved by the other authors.

\section{Funding}

This research received no specific grant from any funding agency, commercial or not-for-profit sectors.

\section{Declaration of interest}

None.

\section{References}

1 World Health Organization Regional Office for the Eastern Mediterranean. About us. WHO, 2021 (http://www.emro.who.int/ entity/about-us/index.html).

2 United Nations Office on Drugs and Crime. Afghanistan Opium Survey 2019. Socio-Economic Survey Report: Drivers, Causes and Consequences of Opium Poppy Cultivation. UNODC, 2021.

3 Al-Imam A, Santacroce R, Roman-Urrestarazu A, Chilcott R, Bersani G, Martinotti G, et al Captagon: use and trade in the Middle East. Hum Psychopharmacol 2017; 32(3).

4 United Nations Office on Drugs and Crime. World Drug Report 2019: Part 5 Cannabis Hallucinogens. UNODC, 2019 (https://wdr. unodc.org/wdr2019/prelaunch/WDR19_Booklet_5_CANNABIS_ HALLUCINOGENS.pdf). 
5 United Nations Office on Drugs and Crime. World Drug Report 2021: Booklet 4 Drug Market Trends: Cocaine, Amphetamine-type Stimulants. UNODC, 2021 (https://www. unodc.org/unodc/en/data-and-analysis/wdr-2021_booklet-4. html).

6 United Nations Office on Drugs and Crime. World Drug Report 2021: Booklet 3 Drug Market Trends: Opioids, Cannabis. UNODC 2021 (https://www.unodc.org/unodc/en/data-and-analysis/wdr2021_booklet-3.html).

7 World Health Organization Regional Office for the Eastern Mediterranean. Health and Well-Being Profile of the Eastern Mediterranean Region: An Overview of the Health Situation in the Region and its Countries in 2019. WHO, 2020.

8 Degenhardt L, Charlson F, Ferrari A, Santomauro D, Erskine H, Mantilla-Herrara A, et al The global burden of disease attributable to alcohol and drug use in 195 countries and territories, 1990-2016: a systematic analysis for the global burden of disease study 2016. Lancet Psychiatry 2018; 5: 987-1012.

9 World Health Organization. Global Health Estimates 2020 Disease Burden by Cause, Age, Sex, by Country and by Region, 2000-2019. WHO, 2020 (https://www.who.int/data/gho/data/ themes/mortality-and-global-health-estimates/global-healthestimates-leading-causes-of-dalys\#: :text=DALYs\%20from $\% 20$ diabetes $\% 20$ increased $\% 20$ by,doubled $\% 20$ between $\% 202000 \%$ 20and\%202019).

10 WHO Forum on Alcohol, Drugs and Addictive Behaviour. Alcohol and Drug Use Disorders: Global Health Estimates. WHO, 2017 (https://www.who.int/substance_abuse/activities/fadab/ msb_adab_2017_GHE_23June2017.pdf).

11 Ritchie H, Roser M. Opioids, Cocaine, Cannabis and Illicit Drugs. Our World in Data, 2018

12 United Nations Office on Drugs and Crime. Regional Overview Asia and Oceania. UNODC, 2020 (https://www.unodc.org/ documents/scientific/Regional_Overview_Asia_and_Oceania. pdf).

13 Abd-Elkader MR, Kabbash IA, El-Sallamy RM, El-Sawy H, Gad E-SA-H. Tramadol abuse among workers in an industrial city in mid-Nile Delta region, Egypt. Environ Sci Pollut Res 2020 27: $37549-56$.

14 Rabie M, Shaker NM, Gaber E, El-Habiby M, Ismail D, El-Gaafary $\mathrm{M}$, et al Prevalence updates of substance use among Egyptian adolescents. Middle East Current Psychiatry 2020; 27(1): 4 .

15 Rostam-Abadi Y, Gholami ], Amin-Esmaeili M, Safarcherati A Mojtabai R, Ghadirzadeh MR, et al Tramadol use and public health consequences in Iran: a systematic review and meta-analysis. Addiction 2020; 115: 2213-42.
16 United Nations Office on Drugs and Crime. World Drug Report 2019: Part 4 Stimulants. UNODC, 2019 (https://wdr.unodc.org/ wdr2019/prelaunch/WDR19_Booklet_4_STIMULANTS.pdf).

17 Wu N, Feng Z, He X, Kwon W, Wang J, Xie X-Q. Insight of captagon abuse by chemogenomics knowledgebase-guided systems pharmacology target mapping analyses. Sci Rep 2019; 9: 2268.

18 Shadloo B, Amin-Esmaeili M, Haft-Baradaran M, Noroozi A, Ghorban-Jahromi R, Rahimi-Movaghar A. Use of amphetamine-type stimulants in the Islamic Republic of Iran, 2004-2015: a review. East Mediterr Health J 2017; 23: 245-56.

19 Crabtree B. The Nexus of Conflict and Illicit Drug Trafficking: Syria and the Wider Region. Global Initiative against Transnational Organised Crime, 2016.

20 Numan N. Exploration of adverse psychological symptoms in Yemeni khat users by the symptoms checklist-90 (SCL-90). Addiction 2004; 99: 61-5.

21 Mahfouz MS, Rahim B-e, Solan YMH, Makeen AM, Alsanosy RM. Khat chewing habits in the population of the Jazan Region, Saudi Arabia: prevalence and associated factors. PLoS One 2015; 10(8): e0134545.

22 Manghi RA, Broers $B$, Khan R, Benguettat $D$, Khazaal $Y$, Zullino DF. Khat use: lifestyle or addiction? J Psychoactive Drugs 2009; 41(1): 1-10

23 Alblooshi H, Hulse GK, El Kashef A, Al Hashmi H, Shawky M, Al Ghaferi $\mathrm{H}$, et al The pattern of substance use disorder in the United Arab Emirates in 2015: results of a national rehabilitation centre cohort study. Subst Abuse Treat Prev Policy 2016; 11(1): 19.

24 Radfar SR, Cousins SJ, Shariatirad S, Noroozi A, Rawson RA. Methamphetamine use among patients undergoing methadone maintenance treatment in Iran; a threat for harm reduction and treatment strategies: a qualitative study. Int J High Risk Behav and Addict 2016; 5(4): e30327.

25 Alinejad S, Aaseth J, Abdollahi M, Hassanian-Moghaddam H, Mehrpour 0 . Clinical aspects of opium adulterated with lead in Iran: a review. Basic Clin Pharmacol Toxicol 2018; 122: 56-64.

26 Ghane T, Zamani N, Hassanian-Moghaddam H, Beyrami A, Noroozi A. Lead poisoning outbreak among opium users in the Islamic Republic of Iran, 2016-2017. Bull World Health Organ 2018; 96: 165-72.

27 Akhgari M, Etemadi-Aleagha A, Jokar F. Street level heroin, an overview on its components and adulterants. In Neuropathology of Drug Addictions and Substance Misuse Vol 1: Foundations of Understanding, Tobacco, Alcohol, Cannabinoids and Opioids (ed VR Preedy): 867-77. Elsevier ScienceDirect, 2016. 